\title{
Coping and Mental Health in Early Adolescence during COVID-19
}

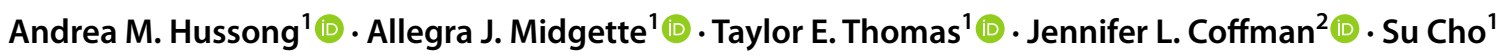

Accepted: 4 April 2021 / Published online: 15 April 2021

(C) The Author(s), under exclusive licence to Springer Science+Business Media, LLC, part of Springer Nature 2021

\begin{abstract}
The current longitudinal study examines changes in overall mental health symptomatology from before to after the COVID-19 outbreak in youth from the southeastern United States as well as the potential mitigating effects of self-efficacy, optimism, and coping. A sample of 105 parent-child dyads participated in the study (49\% boys; 81\% European American, 1\% Alaska Native/American Indian, 9\% Asian/Asian American; 4\% Black/African American; 4\% Latinx; and 4\% other; 87\% mothers; $25 \%$ high school graduate without college education; 30\% degree from 4-year college; $45 \%$ graduate or professional school). Parents completed surveys when children were aged 6-9, 8-12, 9-13, and 12-16, with the last assessments occurring between May 13, 2020 and July 1, 2020 during the COVID-19 outbreak. Children also completed online surveys at ages 11-16 assessing self-efficacy, optimism, and coping. Multi-level modeling analyses showed a within-person increase in mental health symptoms from before to after the outbreak after controlling for changes associated with maturation. Symptom increases were mitigated in youth with greater self-efficacy and (to some extent) problem-focused engaged coping, and exacerbated in youth with greater emotion-focused engaged and disengaged coping. Implications of this work include the importance of reinforcing self-efficacy in youth during times of crisis, such as the pandemic, and the potential downsides of emotionfocused coping as an early response to the crisis for youth.
\end{abstract}

Keywords COVID-19 Coronavirus · Adolescents $\cdot$ Mental health $\cdot$ Pandemic

\section{Coping and Mental Health in Early Adolescence during COVID-19}

Although studies of the impact of the COVID-19 pandemic on a wide array of developmental, health and well-being outcomes on adolescents and children are just emerging, research from around the world suggest that some youth, although not all, may be experiencing elevated mental health symptoms associated with the pandemic (Saurabh \& Ranjan, 2020; Xie et al., 2020; Zhou et al., 2020). However, very few such studies of youth in the United States have been published (see Oosterhoff et al., 2020 as an exception). Moreover, our current understanding of what types of coping strategies mitigate the impact of pandemic-related stressors on

Andrea M. Hussong

hussong@unc.edu

1 Department of Psychology and Neuroscience, University of North Carolina At Chapel Hill, Chapel Hill, NC, USA

2 Department of Human Development and Family Studies, University of North Carolina At Greensboro, Greensboro, NC, USA youth relies primarily on studies of previous illness-related and other forms of trauma (Chew et al., 2020). In the current study, we followed a longitudinal sample from childhood into adolescence that was assessed most recently in the months after the start of the COVID-19 outbreak in the United States. Through the use of an accelerated longitudinal cohort design, we evaluated the change in trajectories of mental health symptoms that coincided with the outbreak. We also tested whether four theoretically-grounded and wellvalidated forms of coping either mitigated or exacerbated increased risk for mental health symptoms, in addition to factors that may reduce a sense of helplessness (i.e., selfefficacy) and negativity (i.e., optimism) sometimes associated with uncontrollable life stressors.

\section{Mental Health and the COVID-19 Pandemic}

Stressors associated with the COVID-19 outbreak are multifaceted, unevenly distributed in society, and impact those across the age spectrum (Mukherjee, 2020; Prime et al., 2020; Fortuna et al., 2020). For youth, noted stressors in emerging studies have mostly focused on ramifications of 
quarantine in the early weeks of the outbreak, including social isolation, changes to routine, and lack of activity. As predicted, cross-sectional studies (Wang et al., 2020; Liu et al., 2020; Power et al., 2020) suggest increases in mental health symptoms among youth following confinement or quarantine (see Sajid et al., Preprint, June 29 2020). Parents report noticing more distress, worry, fear and helplessness in youth in India (Saurabh \& Ranjan, 2020), China (Xie et al., 2020; Zhou et al., 2020) and Italy (see Pisano, Galimi, \& Carniglia, Preprint, April 13 2020), as well as in Spain and Portugal (see Orgiles et al., 2021). These studies are consistent with prior research indicating that quarantine and social isolation occurring during earlier outbreaks (e.g., Ebola, SARS, MERS) are associated with a range of distress indicators including anger, hopelessness, anxiety, and depression (Brooks et al., 2020; Desclaux et al., 2017; Rogers et al., 2020) as well as longitudinal declines in mental health (Loades et al., 2020). Notably, Wu et al. (2009) reported that such declines continued even three years after the SARS outbreak. Despite this suggestive evidence, longitudinal data are sorely needed to identify developmental processes linking experiences of the outbreak with youth mental health during COVID-19 (Wade et al., 2020).

\section{Mitigating Factors}

A few cross-sectional studies have examined potential mitigating factors (Orgilés et al., 2020; Xie et al., 2020). In an online survey of parents in Wuhan from the early days of the outbreak (February, 2020), Xie et al. (2020) found parents who saw their youth as more optimistic about the pandemic also reported fewer depressive symptoms in their youth. In addition, Orgilés et al. (2020) found that Italian, Spanish, and Portuguese parents of 3-18-year-olds who reported that their children used more task-oriented or avoidant coping strategies had fewer mood, sleep, behavioral and cognitive/attentional symptoms, whereas those who used more emotion-oriented coping had more symptoms. Notably, although findings varied somewhat across countries, many parents retrospectively reported no change in symptoms for their children with the pandemic, and many saw their children use task-oriented and avoidant coping.

These results align with prior studies showing that emotion-focused coping (i.e., efforts to regulate emotional states associated with stress exposures), as opposed to problem-focused coping (i.e., efforts to act on or change the source of a stress exposure), is often associated with more distress and behavioral disturbances (Carlo et al., 2012; Compas et al., 1987, 2017). However, these effects may vary depending on whether stressors are viewed as controllable (and thus addressable via problem-focused coping) or uncontrollable (Compas et al., 1991), an important component of coping with pandemic-related stress.
This approach to coping is consistent with research on other infectious diseases. Findings from Yeung and Fung (2007) showed that in a Chinese sample, greater use of emotion-focused coping at the peak of the SARS outbreak reduced anger and sadness, whereas problem-focused coping reduced sadness only in older but not younger adults. In addition, patterns of coping differed over age groups across the outbreak, with younger adults increasing their use of emotion-focused coping faster than older adults during the outbreak. University students were also more likely to use emotion-focused coping than problem-focused coping in response to SARS-related stressful encounters during the outbreak in China (Gan et al., 2004).

None of these prior infectious disease studies of coping, however, involve adolescents. Other research on children who were diagnosed with cancer suggests that a greater differentiation of forms of coping is more helpful for predicting distress from uncontrollable, complex stressors. For example, Compas et al. (2014) showed that greater use of secondary control (efforts to adapt to stress using cognitive reappraisal, positive thinking, or acceptance) and disengagement coping (efforts to disengage from the stress through avoidance, denial, and wishful thinking) were associated with lower rates of anxiety/depressive symptoms, though only secondary control coping was uniquely so.

Attentive to such distinctions in emotion and problem focused coping in the current study, we defined coping according to Tobin and colleagues using the Coping Strategies Inventory (Tobin et al., 1984, 1989). This model distinguishes between emotion- and problem-focused coping styles that involve engaged coping (i.e., in which the goal is to change the situation, one's view of the situation, or how one manages emotion around the stressor) or disengaged coping (i.e., involving denial and avoidance of the situation or one's feelings about the stressor). Following prior studies, we posit that disengaged coping during the pandemic will increase risk for symptomatology in youth by supplanting more engaged attempts to adapt to or alter sources of stress. We anticipate that engaged emotion-focused coping (i.e., involving social support and emotion expression) may reduce risk for mental health symptoms given that these forms of coping may counter the social isolation associated with quarantine. Finally, we expect some benefits of engaged problem focused coping in youth as they adjust to changes in their daily routines surrounding remote learning and scheduling, among other stressors.

In addition to optimism and coping styles, we examined whether changes in mental health symptom trajectories coinciding with the pandemic were mitigated by greater self-efficacy. Self-efficacy has been associated with lower rates of depression (Ehrenberg et al., 1991; Muris, 2002; Tahmassian \& Moghadam, 2011), more positive affect (Caprara et al., 2006), and a greater sense of agency 
(Bandura, 2006), which may promote more active problem solving or coping (Cicognani, 2011). Self-efficacy, in the face of complex stressors, has also been linked to more engaged forms of coping (Dahlbeck \& Lightsey, 2008).

\section{The Current Study}

In the current study, we analyzed data from a longitudinal study originally designed to study the development of gratitude and other-oriented behavior among relatively wellresourced families (i.e., higher social economic status), with the goal of learning how to encourage other-oriented, equity, and justice perspectives and behaviors in youth with social privilege. For this study, the sample provides an examination of how the pandemic impacts youth who are perhaps better resourced (both within the family and within the larger societal structures affected by the pandemic) as one of many groups of interest. Specifically, we tested two primary hypotheses.

H1. We hypothesized that mental health symptoms would increase as a result of the pandemic effect.

$\mathrm{H} 2$. We hypothesized that optimism, self-efficacy, and coping styles would each mitigate the risk for greater within-person symptomatology coinciding with the pandemic.

\section{Method}

\section{Participants and Procedures}

We followed STROBE guidelines for reporting (von Elm et al., 2008). Participants from the Raising Grateful Children study (Hussong et al., 2018) comprised the sample for this longitudinal analysis. The original study was intended to study how parents contribute to child well-being and gratitude across development. We originally recruited participating parents and children from North Carolina, USA in 2013-2014 through mass emails to faculty, staff, and students at an affiliated university, flyers distributed through public and independent schools in first- to third-grade classrooms, and community postings. Inclusion criteria were English proficiency and having a child aged 6-9 years. The analysis sample included parent-child dyads who participated in at least two waves of data collection before and during the pandemic (all but one family), resulting in 105 families (self-reported: $49 \%$ boys; $81 \%$ European American, 1\% Alaska Native/American Indian, 9\% Asian/Asian American, 4\% Black/African American, 4\% Latinx, and 4\% other; $87 \%$ mothers; $25 \%$ high school graduate without college education; $30 \%$ degree from 4-year college; $45 \%$ graduate or professional school graduate).
Families entered the study primarily in wave 1 but four families were added through pilot protocols at waves 2 and 3. At wave 1, children (aged 6-9; mean age 7.4) and a parent completed a lab visit and surveys $(n=100)$. Parents only completed a 2-year follow-up online survey (wave 2 ; children aged 8-12; mean age $9.51 ; \mathrm{n}=102$ ). Parents and children then completed a lab visit and survey at a 3-year follow-up (wave 3; children aged 9-13; $\mathrm{M}=10.6$; $\mathrm{n}=94$ ). And, 90 parents and 88 children (aged 12-16 at wave 4 ; mean age 13.6) completed a six-year follow-up online survey between May 13, 2020 and July 1, 2020. Data collection for all waves received institutional review board approval from The University of North Carolina prior to data collection. Parents provided consent for themselves and their children and children provided assent at the beginning of each lab visit (for waves 1 and 3) and at the beginning of the online survey (in waves 2 and 4, though only parents completed wave 2 ). Participants were compensated for their time ( $\$ 50$ for each family at waves 1 and 3; $\$ 10$ at wave 2 and $\$ 25$ separately for each parent and child in wave 4).

As context, in the county where this study was primarily conducted, executive orders declaring a state of emergency went into effect March $10^{\text {th }}$, with public school closures beginning March $14^{\text {th }}$ and state stay at home orders beginning March 30, 2020. Families in the sample reported experiencing a range of stressors related to COVID-19 during the months of data collection, including youth reporting knowing someone close to them who has COVID-19 symptoms or a diagnosis (19\%), problems with schoolwork (41\%), having to take on more family responsibilities (45\%), being separated from parents due to COVID-19 (11\%), problematic sleep schedules (65\%), and parents reporting being laid off, furloughed, or closing their own businesses (16\%). (See Hussong et al., 2020 for a more detailed report of COVID-19 related stress exposure in this sample).

After wave 3, families were randomly assigned to receive a brief online family communications program to foster gratitude in children either immediately $(n=53)$ or after a one-month delay $(\mathrm{n}=52)$ with all but eight participants completing the program at some point (Hussong et al., 2020a, b). Due to this embedded intervention, we control for treatment exposure (coded as $0=$ control and $1=$ treatment) in subsequent analyses although no effects on children's mental health were found to distinguish the eight non-completers from their peers.

\section{Measures}

Child age was derived from parent-reports of children's date of birth. Parents also reported on child gender, race, and ethnicity at wave 1 . 
Parent-reported Pediatric Symptom Checklist The Pediatric Symptom Checklist was used to assess parent report of child symptomatology (i.e., internalizing and externalizing problems) at waves 1-4 (Jellinek et al., 1988). Prior validation studies show that PSC case classifications (scoring above thresholds on a given subscale) agreed with those from the Child Behavior Checklist (CBCL), Children's Global Assessment Scale (CGAS) ratings of impairment, and the presence of psychiatric disorder in a variety of pediatric and subspecialty settings representing diverse socioeconomic backgrounds (Jellinek et al., 1988, 1991; Murphy et al., 1992, 1996; Rauch et al., 1991). Test/retest reliability of the PSC ranges from $r=0.84-0.91$. Over time, caseness agreement ranged from $83 \%-87 \%$ and kappa $=0.84$ (Jellinek et al. 1988; Murphy et al. 1992). When compared to the CGAS in both middle- and lower-income samples, the PSC has shown high rates of overall agreement $(79 \%$; $92 \%)$, sensitivity $(95 \% ; 88 \%)$, and specificity $(68 \% ; 100 \%$; Jellinek, 1986; Jellinek et al., 1988; Murphy et al., 1992).

Parents indicated how often in the past month their child had exhibited thirty-five behaviors and emotions on a scale ranging from 0 (never) to 2 (often). Items included emotions such as irritability, hopelessness, sadness, and behaviors such as loss of interest in friends, fighting with other children, and having trouble sleeping. Items were averaged at each wave to characterize children's overall symptomatology, with higher scores indicating greater child impairment as reported by parents. (See Table 1 for descriptive statistics for all measures; note that the mean of PSC scores is presented to allow for greater comparability of means and variance across measures).

Child-reported General Self-Efficacy We adapted the General Self-Efficacy Scale to assess children's perceived self-efficacy in wave 4 by deleting two of the original ten items (due to restricted survey length) and simplifying the language (GSE; Schwarzer \& Jerusalem, 1995). The GSE has demonstrated acceptable internal consistency ( $\alpha=0.81$ 0.91 ) and construct validity. Specifically, self-efficacy as measured by the GSE is negatively correlated with depression $(\mathrm{r}=-0.52)$ and anxiety $(\mathrm{r}=-0.60)$, as well as positively associated with optimism $(r=0.55)$ (Schwarzer et al., 1997).

In the current study, children rated the extent to which eight statements related to self-efficacy (e.g., "I can always solve problems if I try hard enough", "I am sure that I can deal with unexpected events") were true for themselves on a scale ranging from 1 (not at all true for you) to 4 (exactly true for you). Items were averaged and used as an indicator of children's perceived self-efficacy.

Child-reported Optimism We used an abbreviated version of the Life Orientation Test-Revised scale (dropping four of the original 10 items due to survey length constraints) for child self-report of optimism in wave 4 (LOT-R; Scheier et al., 1994). The LOT-R scale has demonstrated acceptable internal consistency ( $\alpha=0.78$; Scheier et al., 1994). Additionally, optimism as measured by the LOT-R is associated with selfesteem $(r=0.51)$, life satisfaction $(r=0.39)$, positive affect $(\mathrm{r}=0.32)$, and negative affect $(\mathrm{r}=-0.39)$ in an adolescent sample. It is also associated with aspects of adolescents' psychological well-being, including self-acceptance $(r=0.56)$, autonomy $(r=0.39)$, positive relations $(r=0.37)$, and depressive symptoms ( $\mathrm{r}=-0.43)$ (Monzani et al., 2014).

In this study, children indicated the extent to which statements related to dispositional optimism (e.g., "In uncertain times, I usually expect the best", "I'm always optimistic about the future") described themselves on a scale ranging

Table 1 Scale Descriptive Statistics Across Waves

\begin{tabular}{|c|c|c|c|c|c|c|c|c|c|c|c|}
\hline \multicolumn{2}{|l|}{ Variable } & \multirow{2}{*}{$\begin{array}{l}1 \\
-\end{array}$} & \multirow[t]{2}{*}{2} & \multirow[t]{2}{*}{3} & \multirow[t]{2}{*}{4} & \multirow[t]{2}{*}{5} & \multirow[t]{2}{*}{6} & \multirow[t]{2}{*}{7} & \multirow[t]{2}{*}{8} & \multirow[t]{2}{*}{9} & \multirow[t]{2}{*}{10} \\
\hline 1 & W1 Total Symptoms & & & & & & & & & & \\
\hline 2 & W2 Total Symptoms & $0.73 * * *$ & - & & & & & & & & \\
\hline 3 & W3 Total Symptoms & $0.63 * * *$ & $0.64 * * *$ & - & & & & & & & \\
\hline 4 & W4 Total Symptoms & $0.40 * * *$ & $0.43 * * *$ & $0.61 * * *$ & - & & & & & & \\
\hline 5 & General Self-Efficacy & -0.01 & -02 & -0.05 & $-0.31 *$ & - & & & & & \\
\hline 6 & Optimism & -0.12 & -0.11 & 0.03 & -0.06 & $0.46^{* * *}$ & - & & & & \\
\hline 7 & Problem-Focused Engaged Coping & -0.16 & -0.04 & -0.02 & -13 & $0.54 * * *$ & $0.51^{* * *}$ & - & & & \\
\hline 8 & Emotion-Focused Engaged Coping & -0.12 & -0.01 & -0.08 & -0.02 & $0.30 * *$ & $0.32 * *$ & $0.66 * * *$ & - & & \\
\hline 9 & Problem-Focused Disengaged Coping & -0.18 & -0.03 & 0.05 & 0.02 & $0.30 * *$ & $0.31 * *$ & $0.37 * *$ & $0.32 * * *$ & - & \\
\hline 10 & Emotion-Focused Disengaged Coping & -0.15 & -0.01 & -0.09 & 0.19 & -0.15 & $-0.29 * *$ & -0.03 & 0.08 & $0.36 * * *$ & - \\
\hline MEAN & & 0.44 & 0.38 & 0.42 & 0.57 & 3.15 & 3.34 & 2.91 & 2.78 & 2.65 & 2.18 \\
\hline STD & & 0.24 & 0.27 & 0.24 & 0.30 & 0.58 & 0.70 & 0.91 & 0.92 & 0.63 & 0.90 \\
\hline Reliability $(\alpha)$ & & 0.89 & 0.91 & 0.89 & 0.90 & 0.89 & 0.81 & 0.75 & 0.70 & 0.70 & 0.85 \\
\hline
\end{tabular}

In table $P<0.05 *, P<0.01, * *, P<0.001 * * *$ 
from 1 (strongly disagree) to 5 (strongly agree). Three items were reverse scored and all items were averaged to create a score that characterized children's optimism, with higher scores indicating greater levels of optimism.

Child-reported Coping An adaption of the Coping Strategies Inventory was used to assess children's thoughts and behaviors in response to COVID-19 in wave 4 (Tobin et al., 1984, 1989). Children reflected on the past month of their experiences during COVID-19 and rated the extent to which they used twenty-nine different coping strategies (based on the original scale) on a scale ranging from 1 (not at all) to 5 (very much). Subscales identified by scale developers were calculated by averaging respective items to characterize children's problem-focused engagement (e.g., "I tackled the problem head-on"), emotionfocused engagement (e.g., "I talked to someone about how I was feeling"), problem-focused disengagement (e.g., "I hoped the problem would take care of itself"), and emotion-focused engagement (e.g., "I blamed myself").

\section{Analytical Strategy}

We first examined descriptive analyses to establish the functional form of trajectories. Treating the data like an accelerated longitudinal cohort design, we analyzed developmental trajectories of symptomatology both before (in waves 1-3) and during (in wave 4) the pandemic outbreak, using age as the metric of time and wave as a time-varying indicator of pandemic exposure (coded as ' 0 ' in waves 1-3 and as ' 1 ' in wave 4). This allowed for the testing of the question of whether these factors impacted risk for symptomatology assessed during versus before the pandemic. We present symptomatology patterns in graphical form (see Fig. 1).

We then conducted multi-level modeling analyses to test each of our hypotheses (Bauer \& Curran, 2005; Curran \& Bauer, 2011). We used multiple imputation (PROC MI in SAS/STAT® 14.1 software) to address missing data with 100 imputations that were combined across subsequent analyses using PROC MIANALYZE (with efficiency rates over $99 \%$ across models; $\mathrm{n}=18$ participants had any missing data). We estimated an unconditional model to estimate extent of within- and between-person variance in symptomatology and then analyzed patterns of growth in parentreports of child symptomatology in a conditional baseline model (to establish functional form) with age added as time-varying predictors.

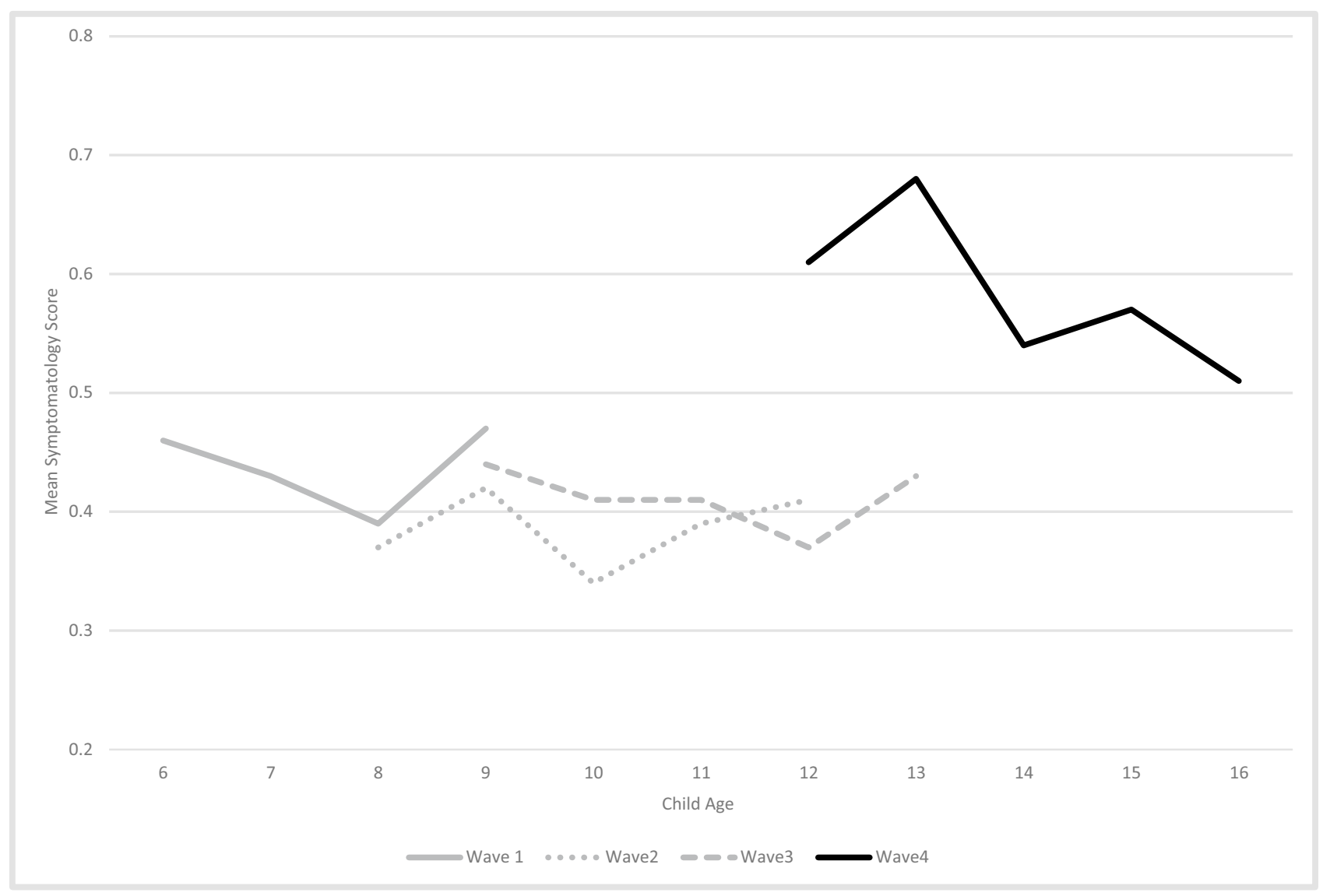

Fig.1 Mean Symptomatology Score by Child Age Across Waves 
To test hypothesis one, we added the pandemic timevarying predictor to this model. We estimated two additional models in which we tested whether pandemic-linked changes in symptomatology differed by gender or race/ethnicity. In line with our second hypothesis, we then tested potential moderators of the pandemic effect on symptomatology; these were included in three separate models testing child general self-efficacy, child optimism, and four forms of coping. To test these effects, we added the main effects of each moderator to the pandemic model as well as the interaction between the moderator and pandemic indicator. We ignored less informative main effects of moderators and focused on interaction effects, which tested the buffering hypothesis. However, all moderators were standardized before model entry.

\section{Results}

\section{Mental Health Trajectories}

Figure 1 depicts mean-levels of symptomatology over age - separated by wave - and shows the two ages of overlap for pre- versus post-pandemic outbreak reporting and the associated jump in symptomatology. Most striking in the figure is the discontinuity in the trajectories for pre- and during-pandemic assessments at ages 12 and 13. Using the PSC cut-score of 28 (Jellinek et al., 1988), only 1 in 30 youth $(3.3 \%)$ aged $12-13$ were above the threshold for problematic symptoms pre-pandemic and 11 in 48 youth (22.9\%) aged 12-13 were above this threshold during the pandemic. These rates compare with an approximate $12 \%$ prevalence rate of psychosocial problems (scores above this threshold) in national estimates (Jellinek et al., 1988, 1991; Little et al., 1994; Murphy et al., 1992, 1996; Rauch et al., 1991). Put another way, the mean sum score for the PSC in pre-pandemic 12-13-year-olds was 13.67 versus 19.94 for 12-13-year-olds assessed during the pandemic. Murphy et al. (2016) note that a difference score of 6 points or greater corresponds to clinically significant change, suggesting that elevations for the overlapping age period from pre to during the pandemic surpass levels of clinical concern.

Using multi-level analysis (in PROC MIXED in SAS) we first estimated an unconditional model (with a random intercept only; estimated on the first imputed dataset to obtain random effects) and found that $51 \%$ of the variance in symptomatology occurred across individuals and $49 \%$ occurred within person over time. To this model, we added the linear effect of age (both fixed and random), with the intercept centered at age 12 and a dummy variable to control for prior program exposure. This model showed that average levels of symptomatology at age 12 were modest, or 0.57 on a $0-2$ scale $(b=0.57 ; t=6.82, p<0.001)$ and the within-person average rate of change in symptoms over time was 0.02 per year $(b=0.02, t=4.16, p<0.001)$ such that symptoms, on average, range from 0.45 at age 6 to 0.65 at age 16 across the linear trajectory.

To test hypothesis one, we then added a fixed-effect pandemic indicator ( 0 for waves $1-3 ; 1$ for wave 4 ) to this model. With the inclusion of the significant pandemic indicator $(b=0.18 ; t=5.49, p<0.001)$, the age trend became non-significant $(b=-0.01 ; t=-1.13, p=0.26)$, suggesting that the age trend in the previous model was due to elevations in symptomatology during the pandemic. Unfortunately, we cannot fully differentiate non-linearity in the age trend from a pandemic effect, but the difference in symptoms at the same ages assessed before and during the pandemic supports the hypothesis that the pandemic and not simply maturation accounts for at least part of this increase in symptomatology.

Finally, we tested whether increases in symptomatology differed in this sample by child gender and race/ethnicity (coded as white versus other races). In these models, we added main effects of gender and race (in separate analyses) to the pandemic model, as well as the interaction between gender or race and the pandemic indicator. Interactions with gender and race were non-significant.

\section{Buffers of Elevated Symptomatology}

In the first model, children with greater self-efficacy indeed showed a smaller pandemic effect or jump in symptomatology from before to during the post COVID-19-outbreak (see Table 2 for multilevel moderating results; note that the mean of PSC scores is presented to allow for greater comparability of means and variance across measures). Probing of simple slopes showed that for those low in self-efficacy, the pandemic lead to a significant increase in symptomatology $(b=0.24 ; t=5.59, p<0.001)$ whereas for those high in self-efficacy, the pandemic effect on symptomatology was still significant but buffered $(b=0.12 ; t=2.84, p<0.01)$. No buffering effect of child optimism was found in the second model.

In the third model, we included four indicators of coping (problem-focused engagement, problem-focused disengagement, emotion-focused engagement, and emotionfocused disengagement) and interactions with the pandemic indicator in the same model. Results showed that two of the four interactions with coping were significant. Probing of simple slopes showed that symptomatology increased more after the pandemic onset for those with greater emotionfocused disengaged coping ( $b=0.24 ; t=5.91, p<0.001)$ and emotion-focused engaged coping $(b=0.25 ; t=5.84$, $p<0.001)$ compared to peers lower on each form of emotion coping $(b=0.11 ; t=2.62, p<0.01$ and $b=0.11, t=2.43$, $p<0.05$, respectively). Moreover, a marginally significant 
Table 2 Fixed-Effect Results for Multilevel Moderating Analyses

\begin{tabular}{|c|c|c|c|c|c|c|}
\hline \multirow[b]{2}{*}{ Fixed-Effect Predictor } & \multicolumn{2}{|c|}{ MODEL $1(n=105)$} & \multicolumn{2}{|c|}{ MODEL $2(n=105)$} & \multicolumn{2}{|c|}{ MODEL $3(n=105)$} \\
\hline & $\begin{array}{l}\text { Estimate } \\
\text { (SD) }\end{array}$ & T-Value & $\begin{array}{l}\text { Estimate } \\
\text { (SD) }\end{array}$ & T-Value & $\begin{array}{l}\text { Estimate } \\
\text { (SD) }\end{array}$ & T-Value \\
\hline Intercept & $0.45(.08)$ & $5.35^{* * *}$ & $0.45(.08)$ & $5.36 * * *$ & $0.45(.08)$ & $5.12 * * *$ \\
\hline Child Age & $-0.01(.01)$ & -1.12 & $-0.01(.01)$ & -1.16 & $-0.01(.01)$ & -1.07 \\
\hline Treatment Control & $-0.07(.09)$ & -0.83 & $-0.07(.09)$ & -0.87 & $-0.06(.09)$ & -0.71 \\
\hline Pandemic & $0.18(.03)$ & $5.52 * * *$ & $0.18(.03)$ & $5.54^{*}$ & $0.08(.03)$ & $5.57 * * *$ \\
\hline General Self-Efficacy & $0.01(.02)$ & 0.06 & & & & \\
\hline General Self-Efficacy x Pandemic & $-0.06(.03)$ & $-2.28 *$ & & & & \\
\hline Optimism & & & $-0.02(.02)$ & -0.99 & & \\
\hline Optimism x Pandemic & & & $-0.01(.03)$ & -0.49 & & \\
\hline Problem-Focused Engaged Coping & & & & & $-0.01(.03)$ & -0.49 \\
\hline Emotion-Focused Engaged Coping & & & & & $-0.02(.03)$ & -0.73 \\
\hline Problem-Focused Disengaged Coping & & & & & $0.02(.03)$ & 0.60 \\
\hline Emotion-Focused Disengaged Coping & & & & & $-0.01(.03)$ & -0.57 \\
\hline Problem-Focused Engaged Coping x Pandemic & & & & & $-0.05(.03)$ & $-1.67+$ \\
\hline Emotion-Focused Engaged Coping x Pandemic & & & & & $0.07(.03)$ & $2.23^{*}$ \\
\hline Problem-Focused Disengaged Coping x Pandemic & & & & & $-0.02(.03)$ & -0.57 \\
\hline Emotion-Focused Engaged Coping x Pandemic & & & & & $0.06(.03)$ & $2.36^{*}$ \\
\hline $\begin{array}{l}\text { Proportion of Variance accounted for by final model } \\
\text { (relative to unconditional model) }\end{array}$ & & $43 \%$ & & $42 \%$ & & $45 \%$ \\
\hline
\end{tabular}

In table $P<0.05 *, P<0.01, * *, P<0.001 * * *$ In single imputation models, degrees of Freedom for within- and between-person effects for Models 1 and 2 are 312 and 102, respectively, and for Model 3 are 309 and 99, respectively. Results reported here, however, for multiple imputation results for which degrees of freedom are estimated by effect

interaction effect suggested that problem-focused engaged coping may serve as a buffer, with those reporting more problem-focused engaged coping showing less increase in symptomatology post-pandemic onset $(b=0.13 ; t=2.77$, $p<0.01)$ compared to their peers low in problem-focused engaged coping $(b=0.23 ; t=5.29 ; p<0.001)$.

\section{Discussion}

In the face of the COVID-19 pandemic, many scholars have turned to considering the impact that the pandemic has on children's and adolescents' mental health. Particularly, prior research has shown that social isolation is associated with increased rates of depression in children and adolescents (Loades et al., 2020). To date, however, most of the recent scholarship has been either commentary aimed at policy or practice or research (Wang et al., 2020; Liu et al., 2020; Power et al., 2020; Ghosh et al., 2020; Golberstein et al., 2020; Mahajan et al., 2020), or cross-sectional empirical studies (see Pisano, Galimi, \& Carniglia, Preprint, April 13 2020; Xie et al., 2020). Importantly, though, there has been rising awareness of the need for a longitudinal and developmental approach to investigating the mental health effects of COVID-19 (Wade et al., 2020).
Results of the current study confirm widely anticipated increases in overall mental health symptoms among young adolescents who were followed from about six years prior to the COVID-19 outbreak to within three to five months after the outbreak in North Carolina. Importantly, these effects track within-person change in symptomatology using an accelerated longitudinal cohort design that permits some parsing of maturation (or age) effects from historical (year of assessment) effects. Thus, the increases in mental health symptoms reported here are not fully attributable to developmental processes.

These findings are consistent with most cross-sectional studies showing evidence of increased mental health symptoms in the earliest months following the COVID-19 outbreak in countries around the world (see Sajid et al., Preprint, June 29 2020). As in prior studies (see Orgilés et al., 2020; Pisano, Galimi, \& Carniglia, Preprint, April 13, 2020; Romero et al., 2020), we assessed symptomatology by parent report. (Note that we also have youth-reports but only at waves 3 and 4 so that even though we see increased symptoms in these data, we cannot differentiate maturational and historical/COVID-19 effects as we could in our four-wave longitudinal parent-report data). We anticipate that several factors may account for differences in the impact of COVID-19 on adolescent mental health across these studies, 
including the country of origin (that differ in responses to both COVID-19 and adolescent mental health, among other things) as well as in time since the outbreak and related sequelae took place. Ongoing studies will further illuminate the significance of these factors.

In addition to these systemic factors, individual differences appear to impact risk for increased mental health symptoms in youth after the pandemic onset. Like others (Xie et al., 2020), we anticipated that youth with a more optimistic perspective would have reduced risk for pandemic-linked increases in symptomatology via lower rates of negative cognitions about the future and the world (which have been linked to depression) (Weeks et al., 2017). However, overall optimism did not mitigate risk, though perhaps if we had assessed optimism regarding the impact of the pandemic specifically, our effects may have mirrored those of Xie et al. (2020).

We did find that higher self-efficacy reduced risk for postpandemic onset increases in symptomatology. Although only a marginally significant effect, problem-focused engaged coping (involving the use of problem-solving skills and cognitive restructuring) also might have a mitigating effect (Tobin et al., 1984, 1989). We posit that these protective factors share a focus on addressing controllable factors associated with pandemic stress and having the confidence that youth are capable of enacting such control. In the current study, the nature of stressors experiencing by youth related to the pandemic were not analyzed. However, we may find that the extent to which these factors are protective differ from groups of youth who experience different types of stressors (e.g., controllable vs. uncontrollable) related to the pandemic (Bhanji et al., 2016; Forsythe \& Compas, 1987).

Finally, we also found that emotion-focused coping increased risk for elevated symptomatology that coincided with the pandemic onset. This was true for both disengaged emotion-focused coping (involving social withdrawal and self-criticism) and emotion-focused engaged coping (involving seeking social support and emotional expression) (Tobin et al., 1984, 1989). It will be informative to study whether these same effects of coping strategies persist among youth as they deal with the cumulative stress associated with the pandemic. The pandemic is lasting longer than some youth and parents may have anticipated (Prime et al., 2020). Given the cumulative nature of stress in impacting functioning (Prime et al., 2020), the early months of the pandemic for youth in early adolescence may have been marked by events at first welcome (e.g., an easing of schoolwork expectations) that over time become more challenging (e.g., a lack of structure, reduced social interaction). These changing perceptions and experiences of pandemic-related stress may call over time for more engaged emotion-focused coping, as what were once viewed as time-limited controllable stressors become more prolonged and less controllable events.
Regardless, our data suggest that a heavy emphasis on emotion coping can exacerbate mental health symptoms coinciding with the early months of the pandemic.

In sum, the current study found increases in mental health symptoms associated with the onset of the COVID-19 pandemic that were mitigated in youth with greater self-efficacy and (to some extent) problem-focused engaged coping and exacerbated in youth with greater emotion-focused engaged and disengaged coping. Strengths of the study include the accelerated cohort longitudinal design, the use of multiple reporter data, and the focus on mental health trajectories. Limitations include sample homogeneity, which did not permit adequately powered tests of racial/ethnic differences, only parent-reports of symptomatology, and modest sample size. As previously noted, the sample represents families with higher levels of educational attainment and that have volunteered to be in a study about parenting and gratitude, limiting generalizability. In this way, we might expect the impact of the pandemic to be less evident than in lessresourced samples (both in terms of being enriched by a parenting program prior to wave 4 and by having a higher educational attainment). Moreover, this study was not designed to consider other important factors that impact response to stress and traumatic events indicated in the literature, including, for example, nature of stress exposure, extent of life disruption, alternate sources of support, parental responses to the stress, and community resources (Boals \& Banks, 2012; Kronenberg et al., 2010; Rousseau et al., 2015). This study was also not designed to assess whether the moderators (i.e., optimism, self-efficacy, and coping) were impacted by the COVID-19 pandemic; rather, the moderators were examined as changing the trajectories of mental health symptoms at the onset of the pandemic. Finally, alternate study designs with a greater age span and age overlap from the pre- to during pandemic periods may shed more light on the impact of the pandemic across development. Implications of this work include the importance of reinforcing self-efficacy in youth during times of crisis, such as the pandemic, and the potential downsides of youths' use of emotion-focused coping as an early response to the crisis.

Author Contributions All authors contributed to the study conception, design, and material preparation. Data collection: Su Cho, Jennifer Coffman, Andrea Hussong, Allegra Midgette, and Taylor Thomas; Analysis: Andrea Hussong. Writing- introduction, figure, and discussion section: Andrea Hussong. Writing-literature review and references: Allegra Midgette. Writing-methods: Taylor Thomas. Writing- Tables: Su Cho. All authors commented on and edited previous versions of the manuscript. All authors read and approved the final manuscript.

Funding Funding for this project was provided by the Expanding the Science and Practice of Gratitude Project run by UC Berkeley's Greater Good Science Center in partnership with UC Davis and by the 
John Templeton Foundation for earlier waves of data collection. For the most recent data collection, funding was provided by the National Center for Advancing Translational Sciences (NCATS), National Institutes of Health, through Grant Award Number UL1TR002489. The writing of this manuscript was supported in part by a postdoctoral fellowship provided by the National Institute of Child Health and Human Development (T32-HD007376) to the second author through the Frank Porter Graham Child Development Institute, University of North Carolina at Chapel Hill.

Code Availability De-identified data and analytic code are available from the first author upon request.

\section{Compliance with Ethical Standards}

Ethics Approval This study was performed in line with the principles of the Declaration of Helsinki. Approval was granted by the Institutional Review Board at the University of North Carolina at Chapel (Date. 05/06/2020/No. 20-1337).

Consent to Participate Informed consent was obtained from all individual participants included in the study. In addition, for participating children and adolescents Informed consent was obtained from legal guardians.

Consent for Publication The authors affirm that human research participants provided informed consent for publication of their data.

Conflicts of Interest/Competing Interests The authors have no relevant financial or non-financial interests to disclose.

\section{References}

Bandura, A. (2006). Adolescent development from an agentic perspective. In F. Pajares \& T. Urdan (Eds.), Self-efficacy beliefs of adolescents. (pp. 1-43). Information Age Publishing.

Bauer, D. J., \& Curran, P. J. (2005). Probing interactions in fixed and multilevel regression: Inferential and graphical techniques. Multivariate Behavioral Research, 40(3), 373-400. https://doi.org/10. 1207/s15327906mbr4003_5

Bhanji, J. P., Kim, E. S., \& Delgado, M. R. (2016). Perceived control alters the effect of acute stress on persistence. Journal of Experimental Psychology: General, 145(3), 356-365. https://doi.org/10. 1037/xge0000137

Boals, A., \& Banks, J. B. (2012). Effects of traumatic stress and perceived stress on everyday cognitive functioning. Cognition \& Emotion, 26(7), 1335-1343. https://doi.org/10.1080/02699931. 2011.651100

Brooks, S. K., Webster, R. K., Smith, L. E., Woodland, L., Wessely, S., Greenberg, N., \& Rubin, G. J. (2020). The psychological impact of quarantine and how to reduce it: rapid review of the evidence. The lancet, 395(10227), 912-920. https://doi.org/10.1016/S01406736(20)30460-8

Caprara, G. V., Steca, P., Gerbino, M., Pacielloi, M., \& Vecchio, G. M. (2006). Looking for adolescents' well-being: Self-efficacy beliefs as determinants of positive thinking and happiness. Epidemiology \& Psychiatric Sciences, 15(1), 30-43. https://doi.org/10.1017/ s1121189x00002013

Carlo, G., Mestre, M. V., McGinley, M. M., Samper, P., Tur, A., \& Sandman, D. (2012). The interplay of emotional instability, empathy, and coping on prosocial and aggressive behaviors. Personality and Individual Differences, 53(5), 675-680. https://doi.org/10. 1016/j.paid.2012.05.022

Chew, Q. H., Wei, K. C., Vasoo, S., Chua, H. C., \& Sim, K. (2020). Narrative synthesis of psychological and coping responses towards emerging infectious disease outbreaks in the general population: Practical considerations for the COVID-19 pandemic. Singapore Medical Journal, 61(7), 350-356. https://doi.org/10.11622/smedj. 2020046

Cicognani, E. (2011). Coping strategies with minor stressors in adolescence: Relationships with social support, self-efficacy, and psychological well-being. Journal of Applied Social Psychology, 41(3), 559-578. https://doi.org/10.1111/j.1559-1816.2011. 00726.x

Curran, P. J., \& Bauer, D. J. (2011). The disaggregation of within-person and between-person effects in longitudinal models of change. Annual Review of Psychology, 62, 583-619. https://doi.org/10.1146/annurev. psych.093008.100356

Compas, B. E. (1987) Coping with stress during childhood and adolescence.. Psychological Bulletin 101 (3):393-403

Compas, B. E., Banez, G. A., Malcarne, V., \& Worsham, N. (1991). Perceived control and coping with stress: A developmental perspective. Journal of Social Issues, 47(4), 23-34. https://doi.org/ 10.1111/j.1540-4560.1991.tb01832.x

Compas, B. E., Desjardins, L., Vannatta, K., Young-Saleme, T., Rodriguez, E. M., Dunn, M., Bemis, H., Snyder, S., \& Gerhardt, C. A. (2014). Children and adolescents coping with cancer: Self- and parent reports of coping and anxiety/depression. Health Psychology, 33(8), 853-861. https://doi.org/10.1037/hea0000083

Compas, B. E., Jaser, S. S., Bettis, A. H., Watson, K. H., Gruhn, M. A., Dunbar, J. P., Williams, E., \& Thigpen, J. C. (2017). Coping, emotion regulation, and psychopathology in childhood and adolescence: A meta-analysis and narrative review. Psychological Bulletin, 143(9), 939-991. https://doi.org/10.1037/bul0000110

Dahlbeck, D. T., \& Lightsey, O. R., Jr. (2008). Generalized selfefficacy, coping, and self-esteem as predictors of psychological adjustment among children with disabilities or chronic illnesses. Children's Health Care, 37, 293-315. https://doi.org/10.1080/ 02739610802437509

Desclaux, A., Badji, D., Ndione, A. G., \& Sow, K. (2017). Accepted monitoring or endured quarantine? Ebola contacts' perceptions in Senegal. Social science \& medicine, 178, 38-45. https://doi.org/ 10.1016/j.socscimed.2017.02.009

Ehrenberg, M. F., Cox, D. N., \& Koopman, R. F. (1991). The relationship between self-efficacy and depression in adolescents. Adolescence, 26(102), 361-374.

Forsythe, C. J., \& Compas, B. E. (1987). Interaction of cognitive appraisals of stressful events and coping: Testing the goodness of fit hypothesis. Cognitive Therapy \& Research, 11(4), 473-485. https://doi.org/10.1007/bf01175357

Fortuna, L. R., Tolou-Shams, M., Robles-Ramamurthy, B., \& Porche, M. V. (2020). Inequity and the disproportionate impact of COVID-19 on communities of color in the United States: The need for a trauma-informed social justice response. Psychological Trauma: Theory, Research, Practice, and Policy, 12(5), 443-445. https://doi.org/10.1037/tra0000889

Gan, Y., Liu, Y., \& Zhang, Y. (2004). Flexible coping responses to severe acute respiratory syndrome-related and daily life stressful events. Asian Journal of Social Psychology, 7(1), 55-66. https:// doi.org/10.1111/j.1467-839X.2004.00134.X

Ghosh, R., Dubey, M.J., Chatterjee, S., \& Dubey, S. (2020). Impact of COVID-19 on children: Special focus on the psychosocial aspect. Minerva Pediatrica, 72(3), 226-235. https://doi.org/10. 23736/S0026-4946.20.05887-9

Golberstein, E., Wen, H., \& Miller, B. F. (2020). Coronavirus disease 2019 (COVID-19) and mental health for children and adolescents 
JAMA Pediatrics. Advance online publication. https://doi.org/10. 1001/jamapediatrics.2020.1456

Hussong, A. M., Coffman, J. L., \& Thomas, T. E. (2020a). Gratitude Conversations: An experimental trial of an online parenting tool. The Journal of Positive Psychology, 15, 267-277. https://doi.org/ 10.1080/17439760.2019.1610484

Hussong, A. M., Midgette, A. J., Richards, A., Petrie, R., Coffman, J. L., \& Thomas, T. E. (2020b). COVID-19 life events spill-over on family functioning and adolescent adjustment. Manuscript Under Review.

Hussong, A. M., Langley, H. A., Coffman, J. L., Halberstadt, A. G., \& Costanzo, P. R. (2018). Parent Socialization of Children's Gratitude. In J. Tudge \& L. Freitas (Eds.), Developing gratitude (pp. 199-219). Cambridge University Press.

Jellinek, M. S., Bishop, S. J., Murphy, J. M., Biederman, J., \& Rosenbaum, J. F. (1991). Screening for dysfunction in the children of outpatients at a psychopharmacology clinic. American Journal of Psychiatry, 148(8), 1031-1036.

Jellinek, M. S., Murphy, J. M., \& Burns, B. J. (1986). Brief psychosocial screening in outpatient pediatric practice. The Journal of Pediatrics, 109(2), 371-378. https://doi.org/10.1016/S0022-3476(86) 80408-5

Jellinek, M. S., Murphy, J. M., Robinson, J., Feins, A., Lamb, S., \& Fenton, T. (1988). Pediatric Symptom Checklist: Screening school-age children for psychosocial dysfunction. Journal of Pediatrics, 112(2), 201-209. https://doi.org/10.1016/s0022-3476(88) 80056-8

Kronenberg, M. E., Hansel, T. C., Brennan, A. M., Osofsky, H. J., Osofsky, J. D., \& Lawrason, B. (2010). Children of Katrina: Lessons learned about postdisaster symptoms and recovery patterns. Child Development, 81(4), 1241-1259. https://doi.org/10.1111/j. 1467-8624.2010.01465.x

Little, M., Murphy, J. M., Jellinek, M. S., Bishop, S. J., \& Arnett, H. L. (1994). Screening 4- and 5-year-old children for psychosocial dysfunction: A preliminary study with the Pediatric Symptom Checklist. Journal of Developmental and Behavioral Pediatrics, 15(3), 191-197.

Liu, J. J., Bao, Y., Huang, X., Shi, J., \& Lu, L. (2020). Mental health considerations for children quarantined because of COVID-19. The Lancet Child \& Adolescent Health, 4(5), 347-349. https:// doi.org/10.1016/S2352-4642(20)30096-1

Loades, M. E., Chatburn, E., Higson-Sweeney, N., Reynolds, S., Shafran, R., Brigden, A., Linney, C., McManus, M. N., Borwick, C., \& Crawley, E. (2020). Rapid systematic review: The impact of social isolation and loneliness on the mental health of children and adolescents in the context of COVID-19. Journal of the American Academy of Child \& Adolescent Psychiatry. Advance online publication. https://doi.org/10.1016/j.jaac.2020.05.009

Mahajan, C., Kapoor, I., \& Prabhakar, H. (2020). Psychological effects of COVID-19 on children of health care workers. Anesthesia \& Analgesia. Advance Online Publication. https://doi.org/10.1213/ ANE.0000000000005034

Monzani, D., Steca, P., \& Greco, A. (2014). Brief report: Assessing dispositional optimism in adolescence-Factor structure and concurrent validity of the Life Orientation Test-Revised. Journal of Adolescence, 37(2), 97-101. https://doi.org/10.1016/j.adolescence. 2013.11.006

Mukherjee, S. (2020). Disparities, desperation, and divisiveness: Coping with COVID-19 in India. Psychological Trauma: Theory, Research, Practice, and Policy, 12(6), 582-584. https://doi.org/ $10.1037 /$ tra0000682

Muris, P. (2002). Relationships between self-efficacy and symptoms of anxiety disorders and depression in a normal adolescent sample. Personality \& Individual Differences, 32(2), 337-348. https://doi. org/10.1016/s0191-8869(01)00027-7
Murphy, J. M., Bergmann, P., Chiang, C., Sturner, R., Howard, B., Abel, M. R., \& Jellinek, M. (2016). The PSC-17: Subscale scores, reliability, and factor structure in a new national sample. Pediatrics, 138(3). https://doi.org/10.1542/peds.2016-0038

Murphy, J. M., Ichinose, C., Hicks, R. C., Kingdon, D., Crist-Whitzel, J., Jordan, P., Feldman, G., \& Jellinek, M. S. (1996). Utility of the Pediatric Symptom Checklist as a psychosocial screen to meet the federal Early and Periodic Screening, Diagnosis, and Treatment (EPSDT) standards: a pilot study. Journal of Pediatrics, 129(6), 864-869.

Murphy, J., Reede, J., Jellinek, M., \& Bishop, S. (1992). Screening for psychosocial dysfunction in inner-city children: further validation of the Pediatric Symptom checklist. American Academy of Child and Adolescent Psychiatry, 31(6), 1105-1111.

Oosterhoff, B., Palmer, C. A., Wilson, J., \& Shook, N. (2020). Adolescents' motivations to engage in social distancing during the COVID-19 pandemic: Associations with mental and social health. Journal of Adolescent Health, 67(2), 179-185. https://doi.org/10. 1016/j.jadohealth.2020.05.004

Orgilés, M., Morales, A., Delvecchio, E., Francisco, R., Mazzeschi, C., Pedro, M., \& Espada, J. P. (2021). Coping behaviors and psychological disturbances in youth affected by the COVID-19 health crisis. Frontiers in Psychology, 12, 845. https://doi.org/10.3389/ fpsyg.2021.565657

Orgilés, M., Morales, A., Delvecchio, E., Mazzeschi, C., \& Espada, J. P. (2020). Immediate psychological effects of the COVID-19 quarantine in youth from Italy and Spain. Frontiers in Psychology, 11, 2986. https://doi.org/10.3389/fpsyg.2020.579038

Pisano, L., Galimi, D., \& Cerniglia, L. (2020). A qualitative report on exploratory data on the possible emotional/behavioral correlates of Covid-19 lockdown in 4-10 years children in Italy. PsyArXiv Preprints. DOI: https://doi.org/10.31234/osf.io/stwbn

Power, E., Hughes, S., Cotter, D., \& Cannon, M. (2020). Youth mental health in the time of COVID-19. Irish Journal of Psychological Medicine. Advance online publication. https://doi.org/10.1017/ ipm.2020.84

Prime, H., Wade, M., \& Browne, D. T. (2020). Risk and resilience in family well-being during the COVID-19 pandemic. American Psychologist, 75(5), 631-643. https://doi.org/10.1037/amp0000660

Rauch, P. K., Jellinek, M. S., Murphy, J. M., Schachner, L., Hansen, R., Esterly, N. B., Prendiville, J., Bishop, S. J., \& Goshko, M. (1991). Screening for psychosocial dysfunction in pediatric dermatology practice. Clinical Pediatrics, 30(8), 493-497.

Rogers, J. P., Chesney, E., Oliver, D., Pollak, T. A., McGuire, P., Fusar-Poli, P., Zandi, M.S., Lewis, G., \& David, A. S. (2020). Psychiatric and neuropsychiatric presentations associated with severe coronavirus infections: a systematic review and meta-analysis with comparison to the COVID-19 pandemic. The Lancet Psychiatry, 7(7), 611-627. https:// doi.org/10.1016/S2215-0366(20)30203-0

Romero, E., López-Romero, L., Domínguez-Álvarez, B., Villar, P., \& Gómez-Fraguela, J. A. (2020). Testing the effects of COVID-19 confinement in Spanish children: The role of parents' distress, emotional problems and specific parenting. International Journal of Environmental Research and Public Health, 17(19), 6975. https://doi.org/10.3390/ijerph17196975

Rousseau, C., Jamil, U., Bhui, K., \& Boudjarane, M. (2015). Consequences of 9/11 and the war on terror on children's and young adult's mental health: a systematic review of the past 10 years. Clinical Child Psychology and Psychiatry, 20(2), 173-193. https:// doi.org/10.1177/1359104513503354

Sajid, M. I., Tariq, J., Waheed, A. A., Najaf, D., Balouch, S. S., \& Abaidullah, S. (2020). SARS-CoV-2 \& Pediatric Mental Health: A Review of Recent Evidence. medRxiv. https://doi.org/10.1101/ 2020.06.28.20136168 
Saurabh, K., \& Ranjan, S. (2020). Compliance and psychological impact of quarantine in children and adolescents due to COVID19 pandemic. Indian Journal of Pediatrics, 87(7), 532-536. https://doi.org/10.1007/s12098-020-033x47-3

Scheier, M. F., Carver, C. S., \& Bridges, M. W. (1994). Distinguishing optimism from neuroticism (and trait anxiety, self-mastery, and self-esteem): A reevaluation of the Life Orientation Test. Journal of Personality \& Social Psychology, 67(6), 1063-1078. https://doi. org/10.1037//0022-3514.67.6.1063

Schwarzer, R., Bäßler, J., Kwiatek, P., Schröder, K., \& Zhang, J. X. (1997). The assessment of optimistic self-beliefs: comparison of the German, Spanish, and Chinese versions of the general selfefficacy scale. Applied Psychology, 46(1), 69-88. https://doi.org/ 10.1111/j.1464-0597.1997.tb01096.x

Schwarzer, R., \& Jerusalem, M. (1995). Generalized self-efficacy scale. In J. Weinman, S. Wright, \& M. Johnston (Eds.), Measures in Health Psychology: A User's Portfolio. Causal and Control Beliefs. (pp. 35-37). Windsor, United Kingdom: NFER-NELSON.

Tahmassian, K., \& Moghadam, N. J. (2011). Relationship between self-efficacy and symptoms of anxiety, depression, worry and social avoidance in a normal sample of students. Iranian Journal of Psychiatry \& Behavioral Sciences, 5(2), 91-98.

Tobin, D.L., Holroyd, K.A., \& Reynolds, R.V.C. (1984). User Manual for the Coping strategies inventory. CSI Manual.

Tobin, D. L., Holroyd, K. A., Reynolds, R. V. C., \& Wigal, J. K. (1989). The hierarchical factor structure of the Coping Strategies Inventory. Cognitive Therapy \& Research, 13(4), 343-361. https://doi. org/10.1007/bf01173478

von Elm, E., Altman, D. G., Egger, M., Pocock, S. J., Gøtzsche, P. C., \& Vandenbroucke, J. P. (2008). STROBE Initiative. . The strengthening the reporting of observational studies in epidemiology (STROBE) statement. Journal of Clinical Epidemiology, 61, 344-349. https://doi.org/10.1016/j.jclinepi.2007.11.008

Wade, M., Prime, H., \& Browne, D. T. (2020). Why we need longitudinal mental health research with children and youth during (and after) the COVID-19 pandemic. Psychiatry Research, 290, 113-143. https://doi.org/10.1016/j.psychres.2020.113143
Wang, G., Zhang, Y., Zhao, J., Zhang, J., \& Jiang, F. (2020). Mitigate the effects of home confinement on children during the COVID-19 outbreak. The Lancet, 395(10228), 945-947. https://doi.org/10. 1016/S0140-6736(20)30547-X

Weeks, M., Coplan, R. J., \& Ooi, L. L. (2017). Cognitive biases among early adolescents with elevated symptoms of anxiety, depression, and co-occurring symptoms of anxiety-depression. Infant \& Child Development, 26(5), e2011. https://doi.org/10.1002/icd.2011

Wu, P., Fang, Y., Guan, Z., Fan, B., Kong, J., Yao, Z., Liu, X., Fuller, C. J., Susser, E., Lu, J., \& Hoven, C. W. (2009). The psychological impact of the SARS epidemic on hospital employees in China: exposure, risk perception, and altruistic acceptance of risk. The Canadian Journal of Psychiatry, 54(5), 302-311. https://doi.org/ 10.1177/070674370905400504

Xie, X., Xue, Q., Zhou, Y., Zhu, K., Liu, Q., Zhang, J., \& Song, R. (2020). Mental health status among children in home confinement during the coronavirus disease 2019 outbreak in Hubei Province. JAMA Pediatrics. Advance online publication. https://doi.org/10. 1001/jamapediatrics.2020.1619

Yeung, D. Y. L., \& Fung, H. H. (2007). Age differences in coping and emotional responses toward SARS: a longitudinal study of Hong Kong Chinese. Aging and Mental Health, 11(5), 579-587. https:// doi.org/10.1080/13607860601086355

Zhou, S. J., Zhang, L. G., Wang, L. L., Guo, Z. C., Wang, J. Q., Chen, J. C., Liu, M., Chen, X., \& Chen, J. X. (2020). Prevalence and socio-demographic correlates of psychological health problems in Chinese adolescents during the outbreak of COVID-19. European Child \& Adolescent Psychiatry, 29(6), 749-758. https://doi.org/ 10.1007/s00787-020-01541-4

Publisher's Note Springer Nature remains neutral with regard to jurisdictional claims in published maps and institutional affiliations. 